\title{
Penguatan Konsep Kombinatorika Siswa SMAN 1 Muara Batu Kabupaten Aceh Utara dalam Menghadapi KSN-K Bidang Matematika 2021
}

\author{
Herizal \\ Program Studi Pendidikan Matematika, FKIP, Universitas Malikussaleh \\ Corresponding Author. Email: herizal_mathedu@unimal.ac.id
}

\begin{abstract}
This community service activity aimed to strengthen students' understanding of the combinatorics concepts in facing the regency-level of National Science Competition (KSN) in field of mathematics in 2021. The activity was carried out in March-April 2021 for six meetings in the form of training/coaching. The training used both discovery and drilling methods. The location of the activity was at SMAN 1 Muara Batu, North Aceh Regency with four students as the subject who have been selected at the school level and selected to participate in the KSN at the regency level. Data analysis was carried out qualitatively by direct observation to observe the improvement of the students' comprehension during the learning process. The result obtained was an improvement of the students' understanding of combinatorics topic. It can be seen in solving problems, the students are able to determine what concepts will be used and able to solve several KSN questions on combinatorics topic.
\end{abstract}

\begin{abstract}
Abstrak: Kegiatan pengabdian kepada masyarakat ini bertujuan untuk menguatkan pemahaman konsep kombinatorika siswa dalam menghadapi Kompetisi Sains Nasional (KSN) bidang matematika tingkat kabupaten tahun 2021. Kegiatan dilaksanakan pada bulan Maret-April 2021 sebanyak enam pertemuan dalam bentuk pelatihan/pembinaan. Pelatihan menggunakan metode penemuan dan latihan. Lokasi pengabdian di SMAN 1 Muara Batu, Kabupaten Aceh Utara dengan subjeknya adalah empat siswa yang telah diseleksi tingkat sekolah dan terpilih untuk mengikuti KSN tingkat Kabupaten. Analisis data dilakukan secara kualitatif dengan cara observasi langsung melihat perkembangan siswa selama proses pelatihan. Hasil yang diperoleh adalah adanya peningkatan pemahaman siswa terhadap materi kombinatorika. Hal itu terlihat dalam menyelesaikan soal, siswa sudah dapat menentukan konsep apa yang akan digunakan serta mampu memecahkan beberapa soal KSN topik kombinatorika.
\end{abstract}

\section{Article History:}

Received: 26-09-2021

Reviewed: 06-10-2021

Accepted: 14-10-2021

Published: 13-11-2021

\author{
Key Words: \\ Combinatorics, \\ KSN, Mathematics \\ Olympiad.
}

\section{Sejarah Artikel:}

Diterima: 26-09-2021

Direview: 06-10-2021

Disetujui: 14-10-2021

Diterbitkan: 13-11-2021

\section{Kata Kunci: \\ Kombinatorika, KSN, Olimpiade Matematika.}

How to Cite: Herizal, H. (2021). Penguatan Konsep Kombinatorika Siswa SMAN 1 Muara Batu Kabupaten Aceh Utara dalam Menghadapi KSN-K Bidang Matematika 2021. Jurnal Pengabdian UNDIKMA, 2(2), 174181. doi:https://doi.org/10.33394/jpu.v2i2.4207

https://doi.org/10.33394/jpu.v2i2.4207

This is an open-access article under the CC-BY-SA License.

\section{Pendahuluan}

Kompetisi Sains Nasional (KSN) merupakan salah satu kompetisi sains rutin tahunan tingkat SD, SMP, dan SMA yang diselenggarakan oleh Kementerian Pendidikan dan Kebudayaan Republik Indonesia. Sebelum tahun 2020, nama KSN adalah Olimpiade Sains Nasional (OSN). Namun, mulai tahun 2020 OSN diganti nama dengan KSN, tetapi substansi di dalamnya tidak berbeda. Saat ini, KSN diselenggarakan oleh Pusat Prestasi Nasional (Puspresnas) Kemendikbud RI, salah satu unit kerja dari Kemendikbud yang membidangi penyelenggaraan berbagai kompetisi di jenjang pendidikan dasar hingga pendidikan tinggi. KSN diselenggarakan sebagai ajang pengembangan kemampuan siswa dalam penguasaan ilmu pengetahuan dan teknologi. Selain itu, pelaksanaan KSN juga dimaksudkan untuk 
meningkatkan wawasan dan kemampuan keilmuan siswa serta untuk menanamkan sikap mental positif, berintegritas dan berakhlak mulia kepada siswa (Puspresnas, 2021).

Dalam KSN, ada sembilan bidang yang diujikan, yaitu matematika, fisika, kimia, informatika/komputer, biologi, astronomi, ekonomi, kebumian, dan geografi. Matematika sebagai sebuah bidang tersendiri yang dilombakan dalam KSN mengukur tiga aspek, yaitu pemecahan masalah, penalaran, dan komunikasi tertulis (Dirjendikdasmen, 2019). Olimpiade matematika terdiri dari beberapa topik, yaitu aljabar, teori bilangan, kombinatorika, dan geometri. Dari empat topik tersebut, salah satu topik yang menjadi perhatian adalah kombinatorika. Kombinatorika merupakan suatu kajian tentang penyusunan objek, pencacahan, dan perhitungan objek dengan sifat-sifat tertentu. Beberapa contoh kajian dalam kombinatorika meliputi aturan perkalian, permutasi, kombinasi, relasi rekurensi, prinsip sarang merpati dan fungsi pembangkit (Rosen, 2012). Dalam silabus olimpiade matematika SMA tahun 2019, materi kombinatorika mencakup prinsip pencacahan (prinsip penjumlahan, prinsip perkalian, permutasi dan kombinasi, penggunaan prinsip pencacahan untuk menghitung peluang suatu kejadian), prinsip rumah merpati (pigeonhole principle, prinsip Dirichlet), dan prinsip paritas (Dirjendikdasmen, 2019). Namun, jika dilihat dalam kurikulum matematika SMA, materi-materi tersebut tidak semua tercakup dalam topik pembelajaran matematika. Di SMA, kajian tentang kombinatorika hanya tentang aturan perkalian, permutasi, kombinasi, dan binomial newton. Selain itu pula, materi-materi tersebut adanya di kelas XII, sedangkan siswa-siswi yang ikut KSN biasanya dipilih dari siswa kelas X dan XI. Akibatnya pemahaman mereka tentang kombinatorika belum memadai.

Salah satu SMA di Kabupaten Aceh Utara yang mengalami permasalahan seperti di atas adalah SMA Negeri 1 Muara Batu. Pihak sekolah menyampaikan bahwa tingkat penguasaan materi kombinatorika siswa di SMA tersebut masih rendah. Siswa juga mengakui hal yang sama. Selama ini, mereka hanya belajar dari solusi soal KSN tahun sebelumnya yang beredar di internet. Akibatnya, siswa tidak dapat memahami materi secara utuh dan terkesan menjadi hafalan. Guru matematika di sekolah tersebut juga menguatkan hal itu, yaitu siswa masih sulit membedakan kapan menggunakan konsep permutasi dan kapan menerapkan konsep kombinasi. Hal itu bermuara pada satu masalah, yaitu rendahnya pemahaman siswa terhadap konsep-konsep dalam kombinatorik. Padahal, pemahaman akan suatu konsep sangatlah penting, sebab salah satu sebab siswa membuat kesalahan dalam menyelesaikan soal adalah karenanya kurangnya pemahaman akan suatu konsep (Abdullah et al., 2015; Herizal et al., 2019).

Berangkat dari permasalahan tersebut, dilaksanakanlah sebuah kegiatan pengabdian kepada masyarakat atas permintaan mitra (pihak sekolah) di SMA Negeri 1 Muara Batu berupa bimbingan terhadap siswa yang akan mengikuti KSN di level kabupaten. Tujuan dari kegiatan tersebut adalah untuk menguatkan pemahaman konsep kombinatorika siswa dalam menghadapi KSN matematika tingkat kabupaten tahun 2021 dengan harapan ada perwakilan dari SMAN 1 Muara Batu yang juara di tingkat kabupaten dan lulus ke tingkat Provinsi.

\section{Metode Pengabdian}

Kegiatan pengabdian kepada masyarakat berupa penguatan pemahaman terhadap materi kombinatorika menggunakan metode penemuan (discovery) dan latihan (drilingl). Metode penemuan dilakukan untuk membuktikan beberapa rumus/persamaan dalam kombinatorika dikarenakan pembuktian matematis dapat meningkatkan pemahaman siswa terhadap suatu konsep (Hersh, 1993). Adapun metode latihan bertujuan agar siswa terbiasa untuk menyelesaikan soal-soal olimpiade. Kegiatan dilaksanakan pada bulan Maret-April 
2021 sebanyak 6 pertemuan. Untuk setiap pertemuan berlangsung selama 120 menit. Lokasi pengabdian di SMAN 1 Muara Batu, Kabupaten Aceh Utara, Aceh dengan subjeknya adalah empat siswa yang telah diseleksi tingkat sekolah dan terpilih untuk mengikuti KSN tingkat Kabupaten.

Adapun langkah-langkah kegiatan pengabdian yang dilakukan meliputi: (1) Penguatan materi kombinatorika yang terdiri dari: aturan perkalian, permutasi dengan unsurunsur yang berbeda, permutasi dengan unsur-unsur yang sama, permutasi siklik, banyaknya solusi linear (kombinasi dengan pengulangan), Binomial Newton, dan Menyelesaikan relasi rekurensi linear; dan (2) pemecahan soal-soal KSN tingkat Kabupaten tahun 2020 dan 2019 berkenaan dengan materi kombinatorika. Analisis data dilakukan secara kualitatif dengan cara melihat perkembangan siswa selama proses pelatihan. Dalam pelaksanaannya, siswa diberikan soal-soal KSN dan soal setara KSN untuk topik kombinatorika. Dari proses penyelesaian soal tersebut dapat dilihat bagaimana tingkat pemahaman siswa terhadap konsep kombinatorika.

\section{Hasil Pengabdian dan Pembahasan}

Kegiatan Pengabdian kepada Masyarakat dilaksanakan selama enam pertemuan. Pertemuan dilaksanakan setiap hari Jumat dan Sabtu pada pertengahan Maret 2021 sampai awal April 2021. Setiap pertemuan berlangsung selama 2 jam, yaitu pada pukul 14.00-16.00 WIB. Adapun rincian kegiatan di setiap pertemuannya dapat dilihat pada tabel berikut.

Tabel 1. Rincian Kegiatan Pengabdian di SMAN 1 Muara Batu

\begin{tabular}{|c|c|c|c|c|}
\hline Pertemuan Ke- & \multicolumn{3}{|c|}{ Hari/Tanggal } & Materi \\
\hline 1 & $\begin{array}{l}\text { Sabtu, } \\
2021\end{array}$ & 20 & Maret & $\begin{array}{l}\text { Overview KSN, Teknik } \\
\text { Masalah }\end{array}$ \\
\hline 2 & $\begin{array}{l}\text { Jumat, } \\
2021\end{array}$ & 26 & Maret & Aturan Perkalian, Permutasi \\
\hline 3 & $\begin{array}{l}\text { Sabtu, } \\
2021\end{array}$ & 27 & Maret & $\begin{array}{l}\text { Kombinasi dan Kombinasi dengan } \\
\text { pengulangan }\end{array}$ \\
\hline 4 & $\begin{array}{l}\text { Jumat, } \\
2021\end{array}$ & 02 & April & Binomial Newton \\
\hline 5 & $\begin{array}{l}\text { Sabtu, } \\
2021\end{array}$ & 03 & April & Relasi Rekurensi Linear \\
\hline 6 & $\begin{array}{l}\text { Sabtu, } \\
2021\end{array}$ & 09 & April & $\begin{array}{l}\text { Pemecahan Soal Kombinatorika KSN } \\
2019 \text { dan } 2020\end{array}$ \\
\hline
\end{tabular}

\section{Pertemuan 1}

Pada pertemuan ini, pembahasannya seputar KSN yang dilanjutkan dengan penjelasan teknik pemecahan masalah matematis. Teknik pemecahan masalah matematis yang dijelaskan terdiri dari menemukan pola, membuat tabel, menerka dan menguji kembali, bergerak mundur, dan bekerja secara induktif (Budhi, 2003; Budhi \& Kartasasmita, 2015). Penjelasan mengenai teknik pemecahan masalah beserta contoh-contohnya penting dijelaskan di awal pertemuan agar siswa tahu bahwa untuk menjawab soal matematika agar tidak hanya berfokus pada penggunaan rumus saja. Hasil dari pemberian materi pada pertemuan ini adalah siswa baru paham bahwa menyelesaikan soal matematika tidak identik langsung dengan penggunaan rumus, tetapi bisa dengan mencoba-coba terlebih dahulu, menemukan pola atau bekerja secara induktif. Teknik-teknik ini juga sangat diperlukan dalam 
menyelesaikan soal KSN kombinatorika sebab sering dalam proses penyelesaian soal, terlebih dahulu diperlukan kejelian untuk menemukan pola. Jika pola sudah didapatkan, maka soal tersebut akan mudah untuk diselesaikan.

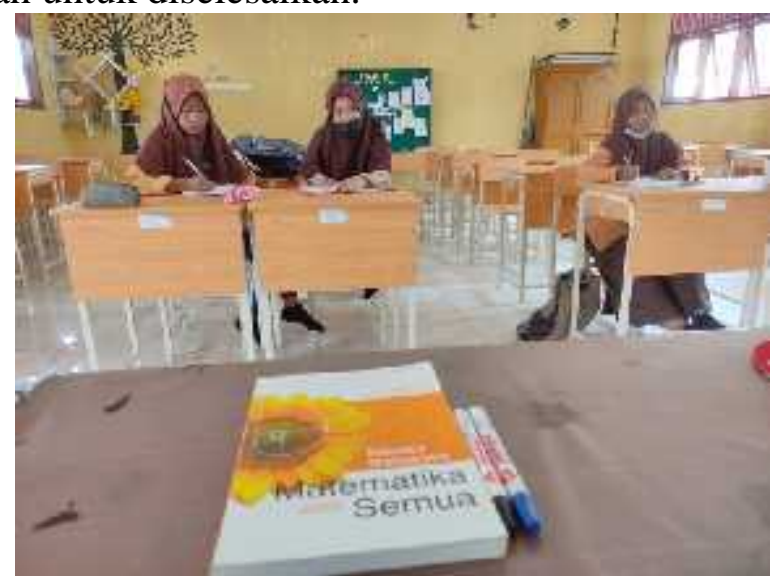

\section{Gambar 1. Siswa Aktif Menyimak Penjelasan Teknik Pemecahan Masalah}

\section{Pertemuan 2}

Pada pertemuan ini, topik yang dibahas adalah aturan perkalian, permutasi linear, permutasi siklik, dan permutasi dengan unsur-unsur yang sama. Pembelajaran menggunakan metode discovery, yaitu pembelajaran yang menekankan pada proses penemuan suatu konsep dan rumus. Dalam hal ini penemuan yang dimaksud adalah proses pembuktian rumus permutasi linear, permutasi siklik, dan permutasi dengan unsur-unsur yang sama. Siswa dibimbing untuk menemukan semua rumus tersebut. Saat proses pembuktian rumus, di situ akan terlihat jelas perbedaan dari konsep permutasi, permutasi siklik, dan permutasi dengan unsur-unsur yang sama. Setelah kegiatan pembuktian tersebut, siswa dapat mengetahui perbedaan dari setiap konsep-konsep tersebut. Hal itu sesuai dengan Hersh (1993) yang menyatakan bahwa kegiatan pembuktian matematis dapat meningkatkan pemahaman siswa akan suatu konsep matematis.

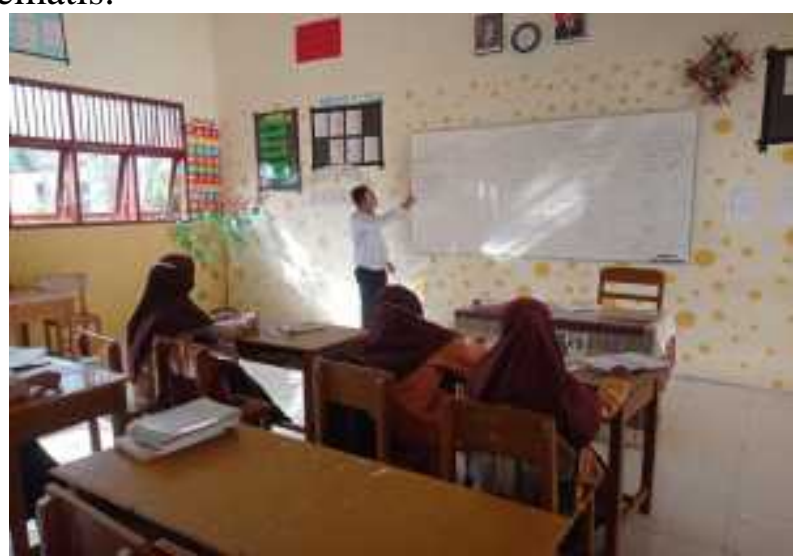

\section{Pertemuan 3}

\section{Gambar 2. Kegiatan Pembuktian Rumus Permutasi}

Pada pertemuan ini, metode yang digunakan masih discovery learning. Siswa dibimbing untuk menemukan rumus kombinasi dan konsep kombinasi dengan pengulangan. Seperti pada pertemuan 2, kegiatan pada pertemuan ini juga untuk meningkatkan pemahaman siswa. Meningkatkan pemahaman siswa memiliki beberapa manfaat, misalnya menambah motivasi siswa. Siswa yang tidak memahami suatu konsep akan merasa putus asa dan tidak 
bersemangat dalam belajar, sedangkan jika siswa memiliki pemahaman yang bagus, mereka akan termotivasi untuk memecahkan masalah. Selain menambah motivasi, pemahaman suatu konsep juga akan mengarahkan siswa untuk pemahaman yang lebih lagi, artinya ketika dihadapkan dengan suatu masalah matematis yang belum dikenal, mereka akan mencoba menggunakan pemahaman yang telah dimiliki untuk menemukan pola-pola baru yang memiliki kesamaan dengan yang telah mereka pelajari (Lambdin, 2003). Hal itu sangat penting saat mempelajari kombinatorika, sebab masalah-masalah kombinatorika itu beragam tetapi memiliki kaitan antar konsep-konsepnya sehingga dengan memahami sebuah konsep, siswa akan dapat menyelesaikan soal-soal yang merupakan perluasan dari konsep tersebut.

\section{Pertemuan 4}

Topik pembahasan dalam pertemuan ini adalah mengenai Binomial Newton. Pembelajaran berfokus untuk mengasah kemampuan siswa melihat pola. Siswa diajak untuk mengingat kembali konstruksi dari segitiga pascal yang telah mereka pelajari saat SMP. Dari segitiga tersebut, siswa diminta untuk melihat jumlah setiap angka-angka yang muncul di setiap barisnya, kemudian meminta untuk melihat pola apa yang terbentuk. Semua siswa mengetahui bahwa jumlah angka-angka dari setiap barisnya berbentuk 2 pangkat angka yang merepresentasikan baris ke berapa. Kemudian siswa diajak untuk melihat pola bahwa angkaangka di segitiga pascal terbentuk dari kombinasi hingga kemudian sampai pada kesimpulan bahwa nilai dari ${ }_{n} \mathrm{C}_{0}+{ }_{n} \mathrm{C}_{1}+{ }_{n} \mathrm{C}_{2}+\ldots+{ }_{n} \mathrm{C}_{\mathrm{n}}=2^{\mathrm{n}}$. Ekspresi wajah siswa terlihat senang ketika sampai pada kesimpulan itu. Saat diberikan soal-soal setara olimpiade yang berkenaan dengan itu, seperti nilai dari " ${ }_{2021} \mathrm{C}_{1}+{ }_{2021} \mathrm{C}_{1}+{ }_{2021} \mathrm{C}_{2}+\ldots+{ }_{2021} \mathrm{C}_{2021}$ adalah ..."” mereka dapat menjawabnya, yaitu $2^{2021}-1$ dimana sebelumnya mereka mengaku bahwa soal itu sulit untuk dipecahkan, ternyata tidak serumit yang dibayangkan. Hal tersebut menunjukkan bahwa pembelajaran untuk menemukan pola sangat penting. Hal ini didukung oleh sebuah studi yang menyatakan bahwa memberikan kesempatan bagi anak-anak untuk terlibat dalam proses matematis berupa proses generalisasi yang berawal dari pola-pola membuat mereka mampu mengabstraksi pola yang lebih kompleks (Papic et al., 2011). Pada pertemuan ini, proses eksplorasi segitiga pascal juga ditekankan untuk menentukan koefisien dari suatu variabel dari sebuah ekspansi binomial, misal berapa koefeisien dari $x^{4}$ dari ekspansi $(2 x+$ $3 y)^{11}$. Soal-soal seperti itu juga sering keluar dalam KSN.

\section{Pertemuan 5}

Topik pada pertemuan ini berkenaan dengan menyelesaikan relasi rekurensi linear. Topik ini merupakan salah satu topik yang sering diuji dalam KSN (lihat Gambar 3) namun tidak diajarkan di dalam pembelajaran matematika reguler SMA. Berangkat dari hal tersebut, diputuskanlah untuk mengajarkan materi menyelesaikan relasi rekurensi linear. Teknik pengajaran pada topik ini adalah menggunakan metode latihan. Pada tahap awal, dijelaskan sedikit teori tentang bagaimana menyelesaikan relasi rekurensi linear yang disertai dengan penjelasan contoh soal. Kemudian siswa diberikan beberapa soal serupa agar mereka terbiasa dengan prosedur-prosedur penyelesaiannya yang lumayan agak panjang. Agar proses pembiasaan itu terjadi, makanya pemilihan metode latihan dirasa cukup tepat sebab metode tersebut bertujuan agar siswa terampil dalam menyelesaikan soal-soal yang pengertian dan prosedurnya sudah dipahami (Suherman et al., 2003). 
5. Suatu barisan bilangan real $a_{1}, a_{2}, a_{3} \ldots$ memcnuhi $a_{1}=1, a_{2}=\frac{3}{5}$, dan

$$
\frac{1}{a_{n}}=\frac{2}{a_{n-1}}-\frac{1}{a_{n_{n}-2}} \text { untuk setiap } n \geq 3
$$

Bilangan $a_{2020}$ dapat ditulis sebagai $\frac{p}{q}$ dengan $p$ can $q$ bilangan asli relatif prima. Nilai $p+q$ adalah...

\section{Gambar 3. Contoh Soal Menyelesaikan Rekurensi Linear pada KSN-K 2020}

\section{Pertemuan 6}

Pada pertemuan ini, fokus kegiatannya adalah pemecahan soal KSN-K bidang matematika tahun 2019 dan 2020 khusus topik kombinatorika. Kegiatan ini sebagai bentuk membiasakan siswa dengan soal KSN. Hasil penelitian menunjukkan bahwa pengalaman menjadi faktor sukses dalam pemecahan masalah (Abdullah et al., 2015). Ada tiga temuan yang didapatkan pada tahapan ini, yaitu: (1) Dibandingkan saat pertemuan awal, pemahaman konsep kombinatorika siswa sudah menunjukkan hasil yang lebih baik. Hal itu terlihat dalam proses penyelesaian soal, mereka sudah tahu bahwa konsep yang digunakan adalah permutasi atau kombinasi; (2) Siswa sudah lancar dalam mencari solusi relasi rekurensi linear yang ada di soal KSN; dan (3) Siswa masih belum lancar untuk menerjemahkan soal cerita ke dalam model matematika, seperti dalam proses penyelesaian soal OSK tahun 2019, mereka masih kesulitan dalam membuat model matematika sehingga mereka tidak tahu bagaimana proses penyelesaiannya. Namun, ketika model matematika telah terbentuk, mereka dengan cepat dapat mengatakan bahwa soal tersebut diselesaikan menggunakan konsep kombinasi dengan pengulangan. Mengenai temuan yang ketiga tentang kesulitan membuat model matematika dari soal cerita yang diberikan, hal tersebut masih menjadi kesulitan bagi siswa secara umum. Hasil penelitian terdahulu menunjukkan hal yang sama, yaitu siswa masih kesulitan dalam membuat model matematika (Jupri \& Drijvers, 2016; Muntaha et al., 2020; Rasiman \& Asmarani, 2016).

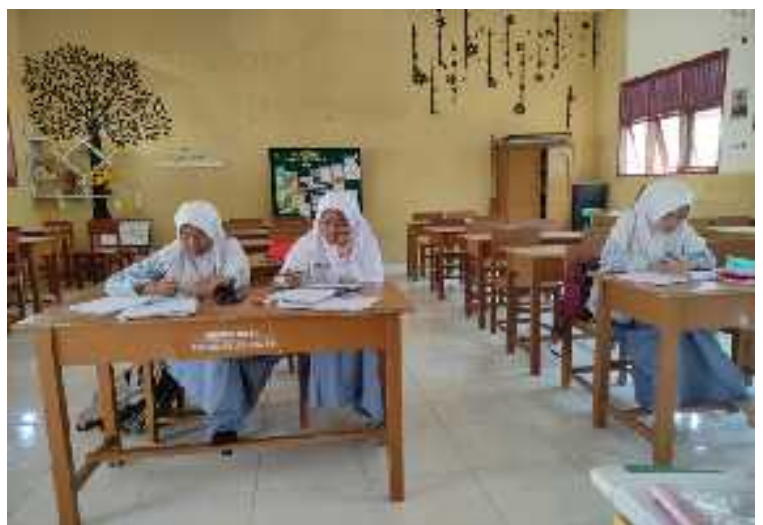

Gambar 4. Siswa Mengerjakan Soal KSN tahun 2019 dan 2020

Melihat perkembangan siswa setelah mengikuti pelatihan materi kombinatorika serta melihat antusiasme siswa selama pelatihan, maka tindak lanjut yang dapat dilakukan adalah memberikan penguatan konsep untuk topik lainnya yang diujikan dalam KSN. Topik yang direncanakan adalah teori bilangan. Pemilihan topik tersebut dikarenakan materi pada teori bilangan seperti teori kongruensi, Algoritma Euclid, Dalil Bezout dan beberapa materi 
lainnya tidak diajarkan secara khusus di SMA melainkan adanya di level Strata-1 (S-1). Oleh karena itu, penguatan konsep teori bilangan sangat penting untuk dilakukan. Diharapkan nantinya siswa mempunyai bekal yang cukup untuk mengikuti KSN dan dapat berhasil hingga jenjang berikutnya.

\section{Kesimpulan}

Kesimpulan yang diperoleh dari kegiatan pengabdian ini antara lain adanya peningkatan pemahaman siswa terhadap materi kombinatorika. Secara detail, siswa telah mampu membedakan antara konsep permutasi dan kombinasi, mampu menyederhanakan suatu deret melalui proses melihat pola dan mengaitkannya dengan konsep yang dipelajari dalam Binomial Newton. Selain itu, mereka juga dapat menyelesaikan solusi linear dari suatu model matematika berbentuk persamaan linear, meskipun pada tahapan menerjemahkan soal cerita ke dalam model matematika masih mengalami kesulitan. Siswa juga sudah lancar dalam mencari solusi relasi rekurensi linear. Secara umum, kegiatan ini telah berdampak terhadap peningkatan kemampuan pemahaman konsep kombinatorika siswa.

\section{Saran}

Dari kegiatan pengabdian yang telah dilaksanakan, beberapa saran yang dapat diberikan kepada pihak sekolah, yaitu kepala sekolah dan guru matematika adalah sebagai berikut: (1) Penguatan kompetensi siswa dalam KSN bidang matematika agar terus rutin dilakukan, tidak hanya ketika akan mengikuti KSN saja; (2) Siswa perlu dibiasakan untuk menyelesaikan menyelesaikan soal-soal KSN tidak hanya saat pelatihan tetapi juga dalam proses pembelajaran dalam kelas reguler; (3) Siswa juga perlu diperkenalkan soal-soal KSN tidak hanya soal level kabupaten, tetapi juga level provinsi dan nasional; dan (4) untuk topik kombinatorika, materi yang diajarkan masih perlu penambahan, seperti materi prinsip sarang merpati (pigeon hole principle) dan fungsi pembangkit.

\section{Daftar Pustaka}

Abdullah, A. H., Abidin, N. L. Z., \& Ali, M. (2015). Analysis of students' errors in solving Higher Order Thinking Skills (HOTS) problems for the topic of fraction. Asian Social Science, 11(21), 133-142. https://doi.org/10.5539/ass.v11n21p133

Budhi, W. S. (2003). Langkah Awal Menuju Ke Olimpiade Matematika. Jakarta: Ricardo.

Budhi, W. S., \& Kartasasmita, B. G. (2015). Berpikir Matematis: Matematika untuk Semua. Jakarta: Erlangga.

Dirjendikdasmen, K. R. (2019). Silabus 2019 Olimpiade Matematika Internasional. Jakarta: Kementerian Pendidikan dan Kebudayaan RI.

Herizal, H., Suhendra, S., \& Nurlaelah, E. (2019). The ability of senior high school students in comprehending mathematical proofs. Journal of Physics: Conference Series, 1157(2). https://doi.org/10.1088/1742-6596/1157/2/022123

Hersh, R. (1993). Proving Is Convincing and Explaining. Educational Studies in Mathematics, 24(4), 389-399.

Jupri, A., \& Drijvers, P. (2016). Student difficulties in mathematizing word problems in Algebra. Eurasia Journal of Mathematics, Science and Technology Education, 12(9), 2481-2502. https://doi.org/10.12973/eurasia.2016.1299a

Lambdin, D. V. (2003). Benefits of teaching through problem solving. In F. K. Lester (Ed.), Teaching Mathematics through Problem Solving: Prekibdergarten - Grade 6 (pp. 313). NCTM. 
Muntaha, A., Wibowo, T., \& Kurniasih, N. (2020). Analisis kesulitan siswa dalam mengonstruksi model matematika pada soal cerita. Maju, 7(2), 53-58.

Papic, M. M., Mulligan, J. T., \& Mitchelmore, M. C. (2011). Assessing the development of preschoolers' mathematical patterning. Journal for Research in Mathematics Education, 42(3), 237-268. https://doi.org/10.5951/jresematheduc.42.3.0237

Puspresnas. (2021). Panduan Pelaksanaan Kompetensi Sains Nasional tahun 2021. Jakarta: Pusat Prestasi Nasional Kemdikbud RI.

Rasiman, \& Asmarani, F. (2016). Analisis Kesulitan Siswa SMP dalam Menyelesaikan Masalah Matematika Ditinjau dari Gaya Kognitif. Jurnal Ilmiah Pendidikan Matematika, 1(2), 195-201.

Rosen, K. H. (2012). Discrete Mathematics and its Applications 7th edition. New York: Mc. Graw Hill, Inc.

Suherman, E., Turmudi, Suryadi, D., Herman, T., Suhendra, Prabawanto, S., Nurjannah, \& Rohayati, A. (2003). Strategi Pembelajaran Matematika Kontemporer. Bandung: Universitas Pendidikan Indonesia. 